\title{
Voltage Harmonic Reduction for Randomly Time-Varying Source Characteristics and Voltage Harmonics
}

\author{
Ahmed Faheem Zobaa, Senior Member, IEEE
}

\begin{abstract}
Potential applications of probabilistic modeling of current and voltage harmonics concern many aspects of power system engineering as accurate prediction of power system harmonic behavior provides important information to utility companies and equipment designers. In this paper, a method of reducing the expected value of the total voltage harmonic distortion for a specified range of source impedance values at different buses by using $\mathrm{LC}$ compensators, where it is desired to maintain a given power factor at a specified value, is presented. The criterion is based on mean value estimation of source and load characteristics, which are enabled by sampling measurements performed on the examined electrical plant as well as statistical analysis.
\end{abstract}

Index Terms-Harmonics, power factor, probability.

\section{INTRODUCTION}

$\mathbf{T}$ HE increasing presence of current and voltage harmonics in distribution and transmission systems is well known. The harmonics are due to the widespread use of nonlinear loads both for efficient energy utilization in residential, commercial, and industrial areas and for increasing the flexibility of power systems; they can seriously damage the system components and operation.

Over the past several years', electric utilities have experienced and research groups have confirmed the nondeterministic nature of harmonics due to continual changes in system configurations, in linear load demands, and in operating modes of nonlinear loads. Taking into account the time-varying nature of harmonics, it is useful to introduce random variables and to apply probabilistic techniques of analysis.

From the energy users point of view, the utility is an equivalent source that either supplies him or her with harmonics, or absorbs harmonics generated by him or her. In this study, both the equivalent source and load are considered to generate harmonics. It is assumed that the load harmonics are not sufficiently serious to suggest tuned filters, but when combined with source harmonics, the use of a pure capacitive compensator would degrade power factor and overload the equipment. The remedy explored here is the insertion of a reactor in series with the local compensating capacitor. This will reduce the energy users' distortion, without regard to his or her neighbors. In such an

Manuscript received September 17, 2004; revised August 8, 2005. Paper no. TPWRD-00441-2004.

The author is with the Electrical Power and Machines Department, Cairo University, Giza 12613, Egypt (e-mail: a.zobaa@eng.cu.edu.eg).

Digital Object Identifier 10.1109/TPWRD.2005.864043 arrangement, the LC compensator may actually have a lower volt-ampere rating (or cost) than that of a pure capacitive compensator [1], [2].

In other attempts at optimizing the LC compensator [3], the main objective has been to maximize the load power factor. This may also reduce the total harmonic distortion of voltage and current, but it may not minimize them. In other words, the problem of minimizing voltage harmonic distortion is not solved by maximizing power factor.

In addition, it is necessary to consider randomly varying source harmonics and impedances. Fixed solutions for one harmonic source condition may not be optimal for another. Therefore, time variations of the harmonics [4], [5] and impedances must be considered in designing optimum capacitors and/or filters [6], [7]. Reference [4] reviews the problems associated with the direct application of the fast Fourier transform (FFT) to compute harmonic levels of nonsteady state distorted waveforms, and various ways to describe recorded data in statistical terms. Each statistical description is applied to a set of recorded data for illustration purposes. Reference [5] includes tools for calculating probabilities of rectangular and phasor components of individual as well as multiple harmonic sources.

A procedure for determining the statistical distribution voltages resulting from dispersed and random current sources is reviewed. Some applications of statistical representation of harmonics are also discussed. If the characteristics of these timevarying quantities are not known apriori, they can be either found by parameters estimation [8]-[10], or measurements [11], [12]. A microcomputer-based parameter estimator [8] for determining the distribution characteristics of a power system is discussed. The use of this parameter estimator is illustrated on an analog of a single-phase feeder. It is found that even in the presence of source harmonics and with a nonlinear load, the system parameters can be determined to a high degree of accuracy. Such measurements can be used in the design of a fixed-components optimal compensator or permit the dynamic control of an online optimal compensator. The measurement of harmonic distortion in power systems is almost always a compromise between the desirable and the possible. In an ideal world, it would be possible to use calibrated voltage dividers with a well-established frequency response connected to the higher voltage system busbars and current transformers with good response in each of the three phases. The reality, however, is different, as the only access given will be to existing voltage transformers and current transformers. The choice of how to calculate harmonics in a power system is also often a compromise, which depends on the 
system information available to the designer and also the purpose for which the calculations are being made. The author [12] discusses the voltage transducers and measurement instruments for harmonics measurement. Calculations in the frequency domain and the time domain are discussed.

In this paper, an optimization criterion of LC compensators to minimize the expected value (EVTHD) of the total voltage harmonic distortion (VTHD) while constraining the power factor (PF) and the values of the compensator which cause resonance. The method is tested by using two case studies taken from previous publications, and the results are compared with other published techniques.

The basic approach to harmonic reduction is first explained, and the objective function expression and analysis are discussed. Then, the suggested optimization algorithm is presented. Finally, the simulated results are discussed.

The major attribute of the method is that unlike conventional approaches, it guarantees convergence to the optimal solution. This accomplishment is a direct result from the improvement in the algorithm in which provisions are made to identify and to avoid compensator values which would create resonance conditions, the problem formulation in which the effect of the Thevenin impedance on the load voltage is included while calculating the optimal compensator value and taking into consideration the manufacturer's standard values for power shunt capacitors.

\section{BASIC APPROACH TO HARMONIC REDUCTION}

Fig. 1 is a single-phase equivalent circuit of a bus with an LC compensator, experiencing voltage harmonic distortion at harmonic order $K$ because of a voltage source $v_{S K}$, and harmonic current sources within the load itself $i_{L K}$.

The Thevenin voltage source representing the utility supply and the harmonic current source representing the nonlinear load is

$$
\mathrm{v}_{\mathrm{S}}(\mathrm{t})=\sum_{\mathrm{K}} \mathrm{v}_{\mathrm{SK}}(\mathrm{t})
$$

and

$$
\mathrm{i}_{\mathrm{L}}(\mathrm{t})=\sum_{\mathrm{K}} \mathrm{i}_{\mathrm{LK}}(\mathrm{t})
$$

where $K$ is the order of harmonic present.

The $K$ th harmonic Thevenin impedance is

$$
\mathrm{Z}_{\mathrm{TK}}=\mathrm{R}_{\mathrm{TK}}+\mathrm{j} \mathrm{X}_{\mathrm{TK}}
$$

and the $K$ th harmonic load impedance is

$$
\mathrm{Z}_{\mathrm{LK}}=\mathrm{R}_{\mathrm{LK}}+\mathrm{j} \mathrm{X}_{\mathrm{LK}}
$$

The $K$ th harmonic compensator impedance is

$$
\mathrm{Z}_{\mathrm{CK}}=\mathrm{R}+\mathrm{j}\left(\mathrm{K} \mathrm{X} \mathrm{X}_{\mathrm{L}}-\mathrm{X}_{\mathrm{C}} / \mathrm{K}\right) \text {. }
$$

To simplify the analysis, only the load model using the respective active and reactive powers at the fundamental frequency is considered while sizing the compensators. This model (Fig. 1) is adequate where VTHD is less than 10\% [13].

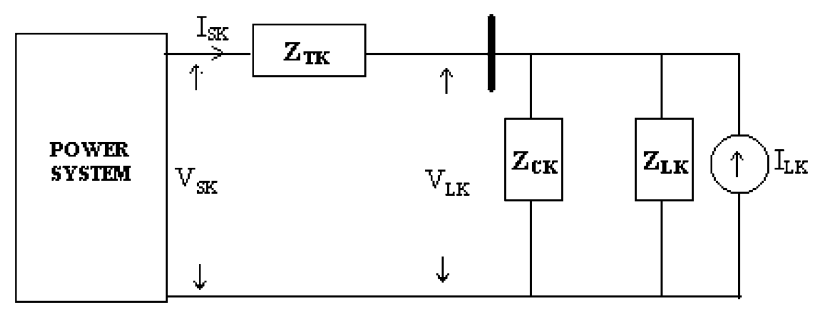

Fig. 1. Single-phase equivalent circuit for the $K$ th harmonic with shunt LC compensator.

The voltage harmonic distortion at the compensated load terminals is defined as

$$
\mathrm{VTHD}=\frac{\sqrt{\sum_{\mathrm{K}>1} \mathrm{~V}_{\mathrm{LK}}^{2}}}{\mathrm{~V}_{\mathrm{L} 1}}
$$

where

$$
\mathrm{V}_{\mathrm{LK}}=\frac{\mathrm{V}_{\mathrm{SK}}(\mathrm{CR})-\mathrm{I}_{\mathrm{LK}}(\mathrm{DR} * \mathrm{ER})}{\mathrm{A}_{\mathrm{IK}}+\mathrm{j} \mathrm{A}_{\mathrm{JK}}}
$$

where

$$
\begin{aligned}
& \text { CR } R_{\mathrm{CLK}}+\mathrm{j} \mathrm{X}_{\mathrm{CLK}} \text {; } \\
& \text { DR } R+j\left(K_{L}-X_{C} / K\right) \text {; } \\
& \text { ER } R_{\mathrm{TLK}}+\mathrm{j} \mathrm{X}_{\mathrm{TLK}} \text {; } \\
& \mathrm{A}_{\mathrm{IK}} \mathrm{R}_{\mathrm{TLK}}+\mathrm{R}\left(\mathrm{R}_{\mathrm{LK}}+\mathrm{R}_{\mathrm{TK}}\right)-\left(\mathrm{X}_{\mathrm{LK}}+\right. \\
& \left.\mathrm{X}_{\mathrm{TK}}\right)\left(\mathrm{KX}_{\mathrm{L}}-\mathrm{X}_{\mathrm{C}} / \mathrm{K}\right) \text {; } \\
& \mathrm{A}_{\mathrm{JK}} \mathrm{X}_{\mathrm{TLK}}+\mathrm{R}\left(\mathrm{R}_{\mathrm{LK}}+\mathrm{X}_{\mathrm{TK}}\right)+\left(\mathrm{R}_{\mathrm{LK}}+\right. \\
& \left.\mathrm{R}_{\mathrm{TK}}\right)\left(\mathrm{KX}_{\mathrm{L}}-\mathrm{X}_{\mathrm{C}} / \mathrm{K}\right) \text {. } \\
& \mathrm{Z}_{\mathrm{CLK}}=\frac{\mathrm{Z}_{\mathrm{LK}} \mathrm{Z}_{\mathrm{CK}}}{\left(\mathrm{Z}_{\mathrm{LK}}+\mathrm{Z}_{\mathrm{CK}}\right)} \\
& =\frac{\left(\mathrm{R}_{\mathrm{CLK}}+\mathrm{j} \mathrm{X}_{\mathrm{CLK}}\right)}{\mathrm{Z}_{\mathrm{LK}}+\mathrm{Z}_{\mathrm{CK}}}
\end{aligned}
$$

where $R_{C L K}$ is $R_{L K}-X_{L K}\left(K_{L}-X_{C} / K\right)$, and $X_{C L K}$ is $\mathrm{RX}_{\mathrm{LK}}+\mathrm{R}_{\mathrm{LK}}\left(\mathrm{KX}_{\mathrm{L}}-\mathrm{X}_{\mathrm{C}} / \mathrm{K}\right)$.

$$
\begin{aligned}
\mathrm{Z}_{\mathrm{TLK}} & =\frac{\mathrm{Z}_{\mathrm{TK}} \mathrm{Z}_{\mathrm{LK}}}{\left(\mathrm{Z}_{\mathrm{TK}}+\mathrm{Z}_{\mathrm{LK}}\right)} \\
& =\frac{\left(\mathrm{RX}_{\mathrm{TLK}}+\mathrm{j} \mathrm{X}_{\mathrm{TLK}}\right)}{\left(\mathrm{Z}_{\mathrm{TK}}+\mathrm{Z}_{\mathrm{LK}}\right)}
\end{aligned}
$$

where $R_{\mathrm{TLK}}$ is $\mathrm{R}_{\mathrm{TK}} \mathrm{R}_{\mathrm{LK}}-\mathrm{X}_{\mathrm{TK}} \mathrm{X}_{\mathrm{LK}}$, and $\mathrm{X}_{\mathrm{TLK}}$ is $\mathrm{R}_{\mathrm{TK}} \mathrm{X}_{\mathrm{LK}}+$ $\mathrm{R}_{\mathrm{LK}} \mathrm{X}_{\mathrm{TK}}$. The compensated PF at the load is given as

$$
\begin{aligned}
\mathrm{PF} & =\frac{\mathrm{P}_{\mathrm{L}}}{\mathrm{V}_{\mathrm{L}} \mathrm{I}_{\mathrm{S}}} \\
& =\frac{\sum \mathrm{G}_{\mathrm{LK}} \mathrm{V}_{\mathrm{LK}}^{2}}{\sqrt{\sum \mathrm{I}_{\mathrm{SK}}^{2} \sum \mathrm{V}_{\mathrm{LK}}^{2}}}
\end{aligned}
$$

where

$$
\begin{aligned}
\mathrm{I}_{\mathrm{SK}} & =\frac{\mathrm{V}_{\mathrm{SK}}(\mathrm{AR}+\mathrm{jBR})+\mathrm{I}_{\mathrm{LK}}(\mathrm{CR})}{\mathrm{A}_{\mathrm{IK}}+\mathrm{j} \mathrm{A}_{\mathrm{JK}}} \\
\mathrm{AR} & =\mathrm{R}+\mathrm{R}_{\mathrm{LK}} \\
\mathrm{BR} & =\left(\mathrm{X}_{\mathrm{LK}}+\mathrm{KX}_{\mathrm{L}}-\mathrm{X}_{\mathrm{C}} / \mathrm{K}\right) \\
\mathrm{Y}_{\mathrm{LK}} & =\mathrm{G}_{\mathrm{LK}}-\mathrm{j} \mathrm{B}_{\mathrm{LK}} .
\end{aligned}
$$

The transmission loss (TL) is given as

$$
\mathrm{TL}=\sum_{\mathrm{K}} \mathrm{I}_{\mathrm{SK}}^{2} \mathrm{R}_{\mathrm{TK}} \text {. }
$$


The network efficiency $(\eta)$ is given as

$$
\begin{aligned}
& \eta=\frac{\mathrm{P}_{\mathrm{L}}}{\mathrm{P}_{\mathrm{S}}} \\
& \eta=\frac{\sum \mathrm{G}_{\mathrm{LK}} \mathrm{V}_{\mathrm{LK}}^{2}}{\sum \mathrm{I}_{\mathrm{SK}}^{2} \mathrm{R}_{\mathrm{TK}}+\sum \mathrm{G}_{\mathrm{LK}} \mathrm{V}_{\mathrm{LK}}^{2}} .
\end{aligned}
$$

The statistical characterization of the input data consists of checking: i) which of the components have to be considered as random in nature and which of them can be kept fixed; ii) what are the statistical features to characterize the random nature of the variables identified in i). With reference to problem ii), the random nature of the nondeterministic components is analyzed by distinguishing the cases of linear loads, generators, and converters; only then is the probabilistic nature of the system admittance terms discussed.

Linear Loads: In the case of balanced power systems, the statistical characterization of linear loads has been fully analyzed [14], considering both dependent and total impedance between load demands.

Converters: If the hypothesis of constant direct current is assumed, then the dc load can be simulated by a direct current generator, whose statistical characterization can be carried out by the knowledge acquired of the expected operational process [15].

Generators: There are no difference between balanced and unbalanced systems because, in both cases, the input data are the three-phase real power. The statistical characterization of the three-phase real power has been fully analyzed, considering both independent and dependent generation systems [14].

System Admittance: The uncertainties of the terms of the system admittance are linked to the system structures and, for an assigned structure, to the values of the electrical parameters of the equivalent circuits of the power system components (line, transformers, etc.). The electrical parameter values of network components at the fundamental frequency could be considered deterministic; at the harmonic frequencies the only uncertainties, which have to be taken into account, are those due to the statistical nature of the linear loads [15].

For randomly time-varying source harmonics and source impedances, the EVTHD must be expressed as a function of $X_{C}$ and $X_{L}$ and of the statistics of random variables. Because distribution system harmonic generators are generally current sources, a positive correlation exists between Thevenin harmonic impedance components $X_{T K}$ and $R_{T K}$, and source harmonic voltage $V_{S K}$, which is a product of source impedances and Norton equivalent current sources. Source voltage, Thevenin resistance, and reactance are linearly correlated to each other at each harmonic order $K>1$ in the most extreme case. Then

$$
\mathrm{V}_{\mathrm{SK}}=\mathrm{G}_{\mathrm{K}} \mathrm{X}_{\mathrm{TK}}
$$

and

$$
\mathrm{R}_{\mathrm{TK}}=\mathrm{T}_{\mathrm{K}} \mathrm{X}_{\mathrm{TK}}
$$

where $G_{K}$ and $T_{K}$ are constants for $K>1$, and $X_{T K}$ is a random variable which is linear with frequency.

Then, the expected value of $V_{L K}$ squared can be written as

$$
\mathrm{E}\left(\mathrm{V}_{\mathrm{LK}}^{2}\right)=\mathrm{E}\left(\frac{\mathrm{d}_{\mathrm{K}} \mathrm{X}_{\mathrm{TK}}^{2}}{\mathrm{c}_{\mathrm{K}} \mathrm{X}_{\mathrm{TK}}^{2}+\mathrm{b}_{\mathrm{K}} \mathrm{X}_{\mathrm{TK}}+\mathrm{a}_{\mathrm{K}}}\right) \text {. }
$$

By definition

$$
E\left(V_{L K}^{2}\right)=\int_{-\infty}^{+\infty} f\left(X_{T K}\right) V_{L K}^{2} d X_{T K}
$$

where $f\left(X_{T K}\right)$ is the probability density function of $X_{T K}$. If the Thevenin reactance $X_{T K}$ is assumed to have a uniform distribution function with minimum value $\beta_{K}$ and maximum value $\gamma_{K}, E\left(V_{L K}^{2}\right)$ from (16) becomes

$$
\begin{aligned}
& E\left(V_{\mathrm{LK}}^{2}\right)=\frac{d_{K}}{\gamma_{K}-\beta_{K}} \int_{\beta_{K}}^{\gamma_{K}} \frac{X_{T K}^{2}}{c_{K} X_{T K}^{2}+b_{K} X_{T K}+a_{K}} d X_{T K} \\
& =\frac{d_{K}}{c_{K}}-\frac{d_{K}}{c_{K}\left(\gamma_{K}-\beta_{K}\right)} \int_{\beta_{K}}^{\gamma_{K}} \frac{b_{K} X_{T K}+a_{K}}{c_{K} X_{T K}^{2}+b_{K} X_{T K}+a_{K}} d X_{T K}
\end{aligned}
$$

where

$$
\begin{array}{ll}
\mathrm{a}_{\mathrm{K}} & \mathrm{b}_{\mathrm{K} 1}^{2}+\mathrm{b}_{\mathrm{K} 2}^{2} ; \\
\mathrm{b}_{\mathrm{K}} & 2 \mathrm{a}_{\mathrm{K} 1} \mathrm{~b}_{\mathrm{K} 1}+2 \mathrm{a}_{\mathrm{K} 2} \mathrm{~b}_{\mathrm{K} 2} ; \\
\mathrm{c}_{\mathrm{K}} & \mathrm{a}_{\mathrm{K} 1}+\mathrm{a}_{\mathrm{K} 2}^{2} ; \\
\mathrm{a}_{\mathrm{K} 1} & \mathrm{~T}_{\mathrm{K}} \mathrm{R}_{\mathrm{LK}}-\mathrm{X}_{\mathrm{LK}}-\left(\mathrm{KX}_{\mathrm{L}}-\mathrm{X}_{\mathrm{C}} / \mathrm{K}\right) ; \\
\mathrm{a}_{\mathrm{K} 2} & \mathrm{~T}_{\mathrm{K}} \mathrm{X}_{\mathrm{LK}}+\mathrm{R}_{\mathrm{LK}}+\mathrm{T}_{\mathrm{K}}\left(\mathrm{KX}_{\mathrm{L}}-\mathrm{X}_{\mathrm{C}} / \mathrm{K}\right) ; \\
\mathrm{b}_{\mathrm{K} 1} & -\mathrm{X}_{\mathrm{LK}}\left(\mathrm{KX}_{\mathrm{L}}-\mathrm{X}_{\mathrm{C}} / \mathrm{K}\right) ; \\
\mathrm{b}_{\mathrm{K} 2} & \mathrm{R}_{\mathrm{LK}}\left(\mathrm{KX}_{\mathrm{L}}-\mathrm{X}_{\mathrm{C}} / \mathrm{K}\right) \\
\mathrm{d}_{\mathrm{K}} & {\left[\mathrm{G}_{\mathrm{K}}^{2}-2 \mathrm{G}_{\mathrm{K}} \mathrm{T}_{\mathrm{K}} \mathrm{I}_{\mathrm{LK}}+\left(\mathrm{T}_{\mathrm{K}}^{2}+1\right) \mathrm{I}_{\mathrm{LK}}^{2}\right]} \\
& \\
& \\
& \left(\mathrm{KX}_{\mathrm{L}}-\mathrm{X}_{\mathrm{C}} / \mathrm{K}\right)^{2}\left(\mathrm{R}_{\mathrm{LK}}^{2}+\mathrm{X}_{\mathrm{LK}}^{2}\right)
\end{array}
$$

The integration of $E\left(V_{L K}^{2}\right)$ for $K>1$ can be calculated [16]. Then, the expected value of $\mathrm{VTHD}^{2}$ can be expressed from (6) as

$$
\mathrm{E}\left(\mathrm{VTHD}^{2}\right)=\frac{\sum_{\mathrm{K}>1} \mathrm{E}\left(\mathrm{V}_{\mathrm{LK}}^{2}\right)}{\mathrm{V}_{\mathrm{L} 1}^{2}} .
$$

System resonant conditions are the most important factors affecting system harmonic levels. Parallel resonance is high impedance to the flow of harmonic current, while series resonance is low impedance to the flow of harmonic current [17]. In actual electrical systems utilizing PF correction, both types of resonance or a combination of both may occur if the resonant point happens to be close to one of the frequencies generated by harmonic sources in the system.

The expected impedance seen from the source is given by

$$
\begin{aligned}
& \mathrm{Z}=\mathrm{Z}_{\mathrm{TK}}+\mathrm{Z}_{\mathrm{CLK}} \\
& \mathrm{Z}=\frac{\left(\mathrm{R}_{\mathrm{TK}}+\mathrm{j} \mathrm{X}_{\mathrm{TK}}\right)+\left(\mathrm{R}_{\mathrm{CLK}}+\mathrm{j} \mathrm{X}_{\mathrm{CLK}}\right)}{\left(\mathrm{Z}_{\mathrm{LK}}+\mathrm{Z}_{\mathrm{CK}}\right)} .
\end{aligned}
$$

The resonance peaks can be obtained by setting the imaginary part of (20) to zero, resulting in a quadratic equation in $X_{C}$ and $X_{L}$ for any given harmonic order $K$

$$
\mathrm{A}_{1}\left(\mathrm{KX}_{\mathrm{L}}-\frac{\mathrm{X}_{\mathrm{C}}}{\mathrm{K}}\right)^{2}+\mathrm{A}_{2}\left(\mathrm{KX}_{\mathrm{L}}-\frac{\mathrm{X}_{\mathrm{C}}}{\mathrm{K}}\right)+\mathrm{A}_{3}=0
$$

where $\mathrm{A}_{1}$ is $\mathrm{X}_{\mathrm{TK}}+\mathrm{X}_{\mathrm{LK}}, \mathrm{A}_{2}$ is the $\mathrm{R}_{\mathrm{LK}}^{2}+\mathrm{X}_{\mathrm{LK}}^{2}+2 \mathrm{X}_{\mathrm{LK}} \mathrm{X}_{\mathrm{TK}}$, and $\mathrm{A}_{3}$ is $\mathrm{R}^{2} \mathrm{X}_{\mathrm{LK}}+\mathrm{X}_{\mathrm{TK}}\left[\left(\mathrm{R}+\mathrm{R}_{\mathrm{LK}}\right)^{2}+\mathrm{X}_{\mathrm{LK}}^{2}\right]$ and by taking the solution of (21) where the square root of the discriminant is positive. (The other solution corresponds to resonance between 
the load and the combination of source impedance and compensator). Note that for sufficiently large load resistance and/or load reactance, (21) reduces to

$$
\mathrm{KX}_{\mathrm{L}}-\frac{\mathrm{X}_{\mathrm{C}}}{\mathrm{K}}+\mathrm{X}_{\mathrm{TK}}=0
$$

which then represents only the series resonance, which represents all possible combinations of $X_{C}$ and $X_{L}$ values which result in resonance between the Thevenin impedance and compensated load. Under these conditions, the PF will reach a minimum. It is evident that the number of series resonance lines will depend on the number of harmonics present in the source.

One problem that is to be addressed is whether the values obtained from theoretical optimization solution can be obtained from the standard manufactured values. Depending on the voltage, manufacturers have discrete capacitive values for the available capacitors. In the presented method, manufacturers' standard values for shunt capacitors are taken into consideration [18]. The standard values are considered as constraints in the sense that the capacitance chosen should be one of these values.

From the above, $E\left(\mathrm{VTHD}^{2}\right), \mathrm{PF}$ and $\eta$ can be expressed as functions of $X_{C}$ and $X_{L}$.

After formulating the objective function and the constraints, the problem addressed in this study becomes

$$
\begin{array}{ll}
\text { Min. } & \mathrm{E}\left(\mathrm{VTHD}^{2}\right)\left(\mathrm{X}_{\mathrm{C}}, \mathrm{X}_{\mathrm{L}}\right) \\
\text { S.t. : } & 90 \% \leq \mathrm{PF}\left(\mathrm{X}_{\mathrm{C}}, \mathrm{X}_{\mathrm{L}}\right) \leq 95 \% \\
& 85 \% \leq \eta\left(\mathrm{X}_{\mathrm{C}}, \mathrm{X}_{\mathrm{L}}\right) \leq 100 \% \\
& \left(\mathrm{X}_{\mathrm{C}}, \mathrm{X}_{\mathrm{L}}\right) \text { is not part of solution of }(21) .
\end{array}
$$

where $\mathrm{PF}$ in distribution systems may be allowed within certain limits according to the operating authority, and similarly for the $\eta$. That is the reason for using these limits.

\section{SugGested Optimization Algorithm}

Each value of the reactive power ratings $Q_{C i}$ of the particular voltage [18] is used to calculate the corresponding value of $X_{C i}$. This value is then substituted into the objective function and constraints to become one variable equation in $X_{L}$.

Then, (23) can be rewritten in the form

$$
\begin{array}{ll}
\text { Min. } & \mathrm{E}\left(\mathrm{VTHD}^{2}\right)\left(\mathrm{X}_{\mathrm{C}}, \mathrm{X}_{\mathrm{L}}\right) \\
\text { S.t. : } & 90 \% \leq \mathrm{PF}\left(\mathrm{X}_{\mathrm{C}}, \mathrm{X}_{\mathrm{L}}\right) \leq 95 \% \\
& 85 \% \leq \eta\left(\mathrm{X}_{\mathrm{C}}, \mathrm{X}_{\mathrm{L}}\right) \leq 100 \% \\
& \left(\mathrm{X}_{\mathrm{Ci}}, \mathrm{X}_{\mathrm{L}}\right) \text { is not part of solution of }(21) .
\end{array}
$$

The precalculated inductor values for series resonance are used to subdivide the entire search region into small regions. The algorithm used in this study can be summarized as follows:

Step 1) Select a value of $Q_{C i}\left\{Q_{C 1} \rightarrow Q_{C n}\right\}$ in kvar [18] where $n$ is the number of discrete values available for the particular voltage rating used. Then, calculate $X_{c i}$ from the following:

$$
\mathrm{X}_{\mathrm{Ci}}=\frac{\mathrm{V}_{\mathrm{S} 1}^{2}}{\mathrm{Q}_{\mathrm{Ci}}} .
$$

Step 2) Starting at an initial point $X_{L}$ in the range of values enclosed by the lowest order resonance peaks will not create resonance condition as stated in (21).

Step 3) Using the Penalty Function method [19] to solve the following problem:

Min. $f\left(X_{L}\right)=E\left(\operatorname{VTHD}^{2}\right)\left(X_{C i}, X_{L}\right)$

$$
+\sum_{\mathrm{m}} \mu_{\mathrm{m}}\left(\max \left[0, g_{\mathrm{m}}\left(\mathrm{X}_{\mathrm{Ci}}, \mathrm{X}_{\mathrm{L}}\right)\right]\right)
$$

where $\mu$ is penalty parameter, $m$ is counter, and $g_{m} s$ are functions described as the following:

$$
\begin{aligned}
& \mathrm{g}_{1}\left(\mathrm{X}_{\mathrm{Ci}}, \mathrm{X}_{\mathrm{L}}\right)=0.9-\mathrm{PF}\left(\mathrm{X}_{\mathrm{Ci}}, \mathrm{X}_{\mathrm{L}}\right) \\
& \mathrm{g}_{2}\left(\mathrm{X}_{\mathrm{Ci}}, \mathrm{X}_{\mathrm{L}}\right)=\mathrm{PF}\left(\mathrm{X}_{\mathrm{Ci}}, \mathrm{X}_{\mathrm{L}}\right)-0.95 \\
& g_{3}\left(\mathrm{X}_{\mathrm{Ci}}, \mathrm{X}_{\mathrm{L}}\right)=0.85-\eta\left(\mathrm{X}_{\mathrm{Ci}}, \mathrm{X}_{\mathrm{L}}\right) \\
& \mathrm{g}_{4}\left(\mathrm{X}_{\mathrm{Ci}}, \mathrm{X}_{\mathrm{L}}\right)=\eta\left(\mathrm{X}_{\mathrm{Ci}}, \mathrm{X}_{\mathrm{L}}\right)-1.0 .
\end{aligned}
$$

For a certain value of $\mu_{m}^{(J)}$, the Golden search method [19] can be applied for obtaining the optimal $X_{L}^{J+1}$ where $J$ is counter.

Step 4) If $\mu_{m}^{(J)}\left(\max \left[0, g_{m}\left(X_{C i}, X_{L}^{(J+1)}\right)\right]\right)<\varepsilon$ where $\varepsilon$ is a preselected small positive number $(\varepsilon \ll 1)$, then terminate the iterative procedure and go to step 1 . If the stopping criterion is not satisfied, then update the value of $\mu_{m}^{(J)}$ using

$$
\mu_{m}^{(\mathrm{J}+1)}=\beta \mu_{\mathrm{m}}^{(\mathrm{J})}
$$

where $\beta$ is a scalar. Then, return to step 3 . Step 5) Compare all of the local minima and find the global minimum.

Reference [20] shows that the starting penalty parameter value $\mu^{(0)}=10$. Values of $\beta$ in the range $0.1-0.5$ work well for most problems. In the optimization process, the resistance of the compensator reactor has been neglected due to its small value with respect to its fundamental reactance (less than 5\%) [2].

\section{Simulated Results AND Discussion}

Two cases of an industrial plant were simulated using the optimization method. The numerical data in case 1 were primarily taken from an example in [3] where the inductive three-phase load is $5100 \mathrm{~kW}$ with a displacement factor (dPF) of $71.65 \%$ and harmonic current sources are listed in Table I. The 60-cycle supply bus voltage and Thevenin impedance are $4.16 \mathrm{kV}$ line to line and $(0.01154+j 0.1154) \Omega$, respectively. Fundamental parameters and load harmonics were assumed to be time-invariant quantities. The voltage-source harmonics and Thevenin impedance for $K>1$ were assumed to be randomly timevarying quantities with their expected values as listed in Table I and their standard deviation $(\sigma)$ equal to $5 \%$. The source and load were arbitrarily chosen to have the same harmonic content as suggested in [3]. These harmonic magnitudes are generally independent. The parameter values of the above cases were then applied to the optimization algorithm and the optimization results are described below. 
TABLE I

SYSTEM PARAMETERS AND SOURCE HARMONICS

\begin{tabular}{|c|c|c|}
\hline Parameters \& Harmonics & Case 1 & Case 2 \\
\hline $\mathrm{R}_{\mathrm{T} 1}[\Omega]$ & 0.01154 & 0.01154 \\
\hline $\mathrm{X}_{\mathrm{T} 1}[\Omega]$ & 0.1154 & 0.1154 \\
\hline $\mathrm{E}\left(\mathrm{X}_{\mathrm{T} 5}\right)[\Omega]$ & 0.5570 & 0.5570 \\
\hline $\mathrm{E}\left(\mathrm{X}_{\mathrm{T} 7}\right)[\Omega]$ & 0.8078 & 0.8078 \\
\hline $\mathrm{E}\left(\mathrm{X}_{\mathrm{T} 11}\right)[\Omega]$ & 1.2694 & 1.2694 \\
\hline $\mathrm{E}\left(\mathrm{X}_{\mathrm{T} 13}\right)[\Omega]$ & 1.5002 & 1.5002 \\
\hline $\mathrm{RL}_{1}[\Omega]$ & 1.7421 & 1.7421 \\
\hline $\mathrm{XL}_{1}[\Omega]$ & 1.6960 & 1.6960 \\
\hline $\mathrm{V}_{\mathrm{S} 1}[\mathrm{~V}]$ & 2400. & 2400. \\
\hline $\mathrm{E}\left(\mathrm{V}_{\mathrm{S} 5}\right)\left[\% \mathrm{~V}_{\mathrm{S} 1}\right]$ & 5 & 1 \\
\hline $\mathrm{E}\left(\mathrm{V}_{\mathrm{S} 7}\right)\left[\% \mathrm{~V}_{\mathrm{S} 1}\right]$ & 3 & 7 \\
\hline $\mathrm{E}\left(\mathrm{V}_{\mathrm{S} 11}\right)\left[\% \mathrm{~V}_{\mathrm{S} 1}\right]$ & 2 & 2 \\
\hline $\mathrm{E}\left(\mathrm{V}_{\mathrm{S} 13}\right)\left[\% \mathrm{~V}_{\mathrm{S} 1}\right]$ & 1 & 1 \\
\hline $\mathrm{I}_{\mathrm{L} 5}\left(\% \mathrm{I}_{\mathrm{S} 1}\right)$ & 5 & 5 \\
\hline $\mathrm{I}_{\mathrm{L} 7}\left(\% \mathrm{I}_{\mathrm{S} 1}\right)$ & 3 & 3 \\
\hline $\mathrm{I}_{\mathrm{L} 11}\left(\% \mathrm{I}_{\mathrm{S} 1}\right)$ & 2 & 1 \\
\hline $\mathrm{I}_{\mathrm{L} 13}\left(\% \mathrm{I}_{\mathrm{S} 1}\right)$ & 1 & \\
\hline & & \\
\hline & & 5 \\
\hline
\end{tabular}

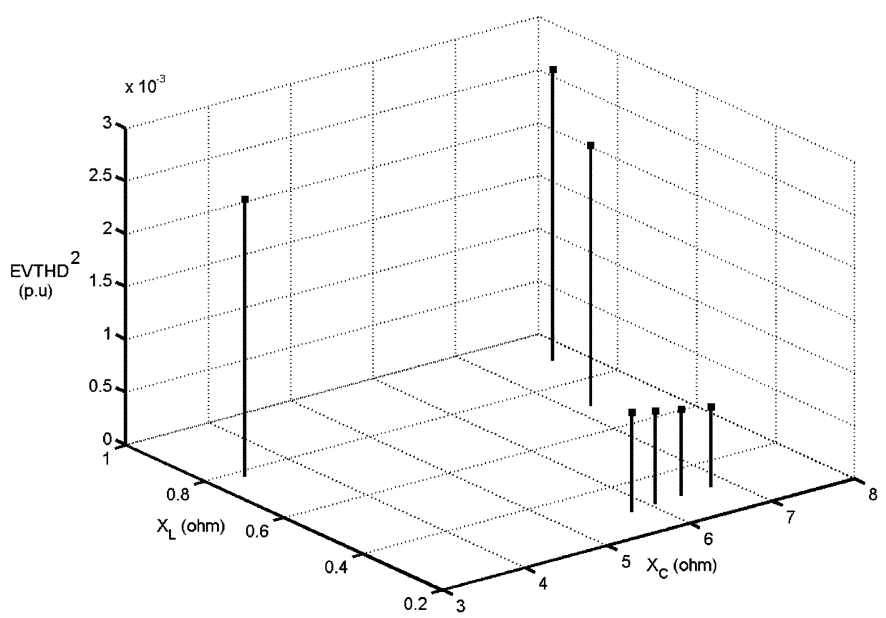

Fig. 2. Global minimum points for case 1 during the search method.

Figs. 2 and 3 show the improvement in choosing the value of $X_{C}$ and $X_{L}$ during the search method and how it affects the objective function.

Now we compare the proposed method with simulated results presented in [21] where the proposed method is applied to the same cases under study neglecting the uncertainty of the source and load characteristics (Table III). The problem addressed in [21] is

$$
\begin{array}{ll}
\text { Min. } & \operatorname{VTHD}\left(\mathrm{X}_{\mathrm{Ci}}, \mathrm{X}_{\mathrm{L}}\right) \\
\text { S.t. : } & 90 \% \leq \mathrm{PF}\left(\mathrm{X}_{\mathrm{Ci}}, \mathrm{X}_{\mathrm{L}}\right) \leq 100 \% \\
& \left(\mathrm{X}_{\mathrm{Ci}}, \mathrm{X}_{\mathrm{L}}\right) \text { is not part of solution of (21). }
\end{array}
$$

Source and load harmonics as well as impedances are generally time-varying at random. An optimal LC compensator designed for the mean values of those random variables (Table III) does not necessarily render an optimum average power factor (Table II) and may even be overloaded when implemented to the time-varying case. Therefore, time variations of the harmonics and impedances must be considered in designing an optimal fixed LC compensator.

Table IV shows the required capacitive reactance, the power factor, the supply current, the efficiency, and the transmission loss for the load being linear and neglecting the uncertainty of the source and load characteristics [22].

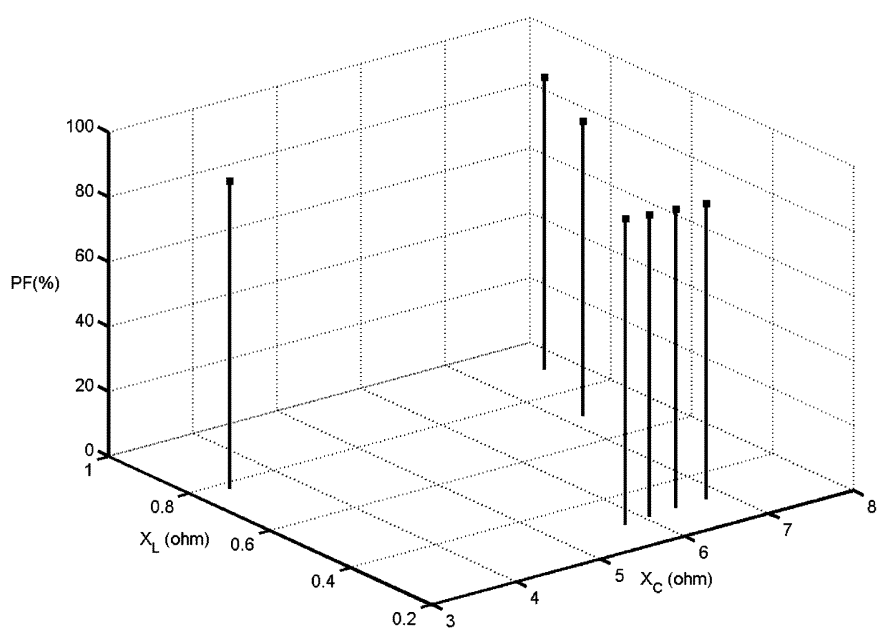

Fig. 3. Power factor values for global minimum points of case 1 .

TABLE II

Simulated Results FOR THE PRESENTEd Optimization Method

\begin{tabular}{|l|c|c|}
\hline Parameter & Case 1 & Case 2 \\
\hline $\mathrm{Q}_{\mathrm{C}}[\mathrm{Kvar}]$ & 850. & 850. \\
\hline $\mathrm{X}_{\mathrm{C}}[\Omega]$ & 6.78 & 6.78 \\
\hline $\mathrm{X}_{\mathrm{L}}[\Omega]$ & 0.3090 & 0.3090 \\
\hline $\mathrm{PF}[\%]$ & 91.06 & 91.14 \\
\hline $\mathrm{dPF}[\%]$ & 91.23 & 91.23 \\
\hline $\mathrm{I}_{\mathrm{S}}[\mathrm{A}]$ & 778.40 & 766.32 \\
\hline$\eta[\%]$ & 99.57 & 99.59 \\
\hline $\mathrm{TL}[\mathrm{kW}]$ & 6.99 & 6.78 \\
\hline $\mathrm{ITHD}[\%]$ & 22.16 & 13.01 \\
\hline $\mathrm{VTHD}[\%]$ & 2.85 & 4.67 \\
\hline EVTHD $[\%]$ & 2.74 & 4.40 \\
\hline
\end{tabular}

TABLE III

SiMULATED RESUlTS FOR THE OPTIMIZATION METHOD IN [21]

\begin{tabular}{|c|c|c|}
\hline Parameter & Case 1 & Case 2 \\
\hline $\mathrm{Q}_{\mathrm{C}}[$ Kvar] & 850. & 850. \\
\hline $\mathrm{X}_{\mathrm{C}}[\Omega]$ & 6.78 & 6.78 \\
\hline $\mathrm{X}_{\mathrm{L}}[\Omega]$ & 0.3085 & 0.3085 \\
\hline $\mathrm{PF}[\%]$ & 89.12 & 90.38 \\
\hline $\mathrm{dPF}[\%]$ & 91.23 & 91.23 \\
\hline $\mathrm{I}_{\mathrm{S}}[\mathrm{A}]$ & 777.58 & 766.28 \\
\hline$\eta[\%]$ & 99.57 & 99.59 \\
\hline $\mathrm{TL}[\mathrm{kW}]$ & 6.98 & 6.78 \\
\hline $\mathrm{ITHD}[\%]$ & 21.69 & 12.99 \\
\hline $\mathrm{VTHD}[\%]$ & 2.83 & 4.46 \\
\hline
\end{tabular}

The most important concepts to be illustrated involve the evaluation of harmonic current limits at individual customers and harmonic voltage limits on the overall system. These limits are typically evaluated at the point of common coupling between the supplier and the customer. In the IEEE Standard 519-1992 [17], the objectives of the nonlinear load harmonic current limits are to limit the maximum individual harmonic voltage to $3 \%$ of the fundamental voltage and the total harmonic distortion of the voltage to $5 \%$. Fig. 4 shows the values of the load harmonic voltage after compensation.

Fig. 4 shows that the resultant values all come out well within standard limits except the seventh harmonic for case 2 . Thus, to reduce voltage distortion, two factors can be modified: the level of harmonic currents, and transformer impedance. Using phaseshifting techniques may reduce the level of harmonic currents, and low impedance plays a crucial role in reducing voltage distortion. Now, low-impedance phase-shifting transformers [23] 
TABLE IV

SiMULATED RESULTS FOR THE OPTIMIZATION METHOD IN [22]

\begin{tabular}{|c|c|c|c|c|c|}
\hline Case & $\mathrm{X}_{\mathrm{C}}(\Omega)$ & $\mathrm{PF}(\%)$ & $\mathrm{I}_{\mathrm{S}}(\mathrm{A})$ & $\eta(\%)$ & $\mathrm{TL}(\mathrm{kW})$ \\
\hline 1 & 3.02 & 91.66 & 770.77 & 99.25 & 6.86 \\
\hline 2 & 2.85 & 87.22 & 812.64 & 99.18 & 7.62 \\
\hline
\end{tabular}

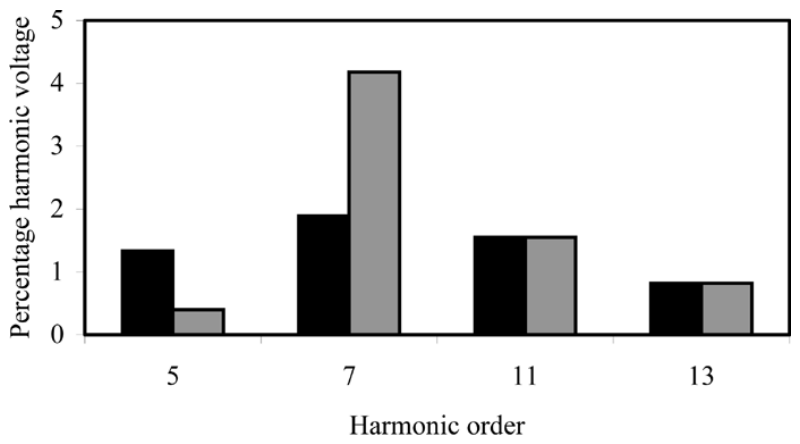

Case $1 \square$ Case 2

Fig. 4. Perecntage of harmonic voltage of the load after compensation.

have thus been designed. They allow the treatment of harmonic currents while providing a path of low impedance. The quality and reliability of the electrical system can thus be considerably improved through the use of a single piece of equipment.

IEEE Standard 18-2002 [18] specifies the following continuous capacitor ratings:

1) $135 \%$ of rated rms current $\left(I_{C}\right)$, including fundamental and harmonic current

$$
\mathrm{I}_{\mathrm{C}}=\sqrt{\sum_{\mathrm{K}} \mathrm{I}_{\mathrm{CK}}^{2}}
$$

where the capacitor current at harmonic number $K$ and $\mathrm{I}_{\mathrm{CK}}$ is given

$$
I_{\mathrm{CK}}=\frac{V_{\mathrm{SK}}\left(R_{\mathrm{LK}}+j X_{\mathrm{LK}}\right)-\mathrm{I}_{\mathrm{LK}}\left(\mathrm{R}_{\mathrm{TLK}}+\mathrm{j} \mathrm{X}_{\mathrm{TLK}}\right)}{\mathrm{A}_{\mathrm{IK}}+\mathrm{j} \mathrm{A}_{\mathrm{JK}}}
$$

2) $110 \%$ of rated rms voltage $\left(V_{C}\right)$, including harmonics but excluding transients

$$
\mathrm{V}_{\mathrm{C}}=\sqrt{\sum_{\mathrm{K}} \mathrm{V}_{\mathrm{CK}}^{2}}
$$

where the capacitor voltage at harmonic number $K$ and $\mathrm{V}_{\mathrm{CK}}$ is given

$$
\mathrm{V}_{\mathrm{CK}}=\frac{\mathrm{I}_{\mathrm{CK}} * \mathrm{X}_{\mathrm{C}}}{\mathrm{K}} .
$$

3) $135 \%$ of nameplate $\operatorname{kvar}\left(\mathrm{Q}_{\mathrm{C}}\right)$

$$
\mathrm{Q}_{\mathrm{C}}=\mathrm{V}_{\mathrm{C}} * \mathrm{I}_{\mathrm{C}} \text {. }
$$

The following is the illustration of the calculation of the capacitor duty of the compensator for case 1.

1) capacitor current distortion $=25.35 \%$;

2) rms capacitor current $=374.99 \mathrm{~A}$;

3) fundamental capacitor current $=353.90 \mathrm{~A}$; capacitor voltage distortion $=4.05 \%$;

4) rms capacitor voltage $=4276.89 \mathrm{~V}$;

5) fundamental capacitor voltage $=4273.60 \mathrm{~V}$.

Table V shows the calculated capacitor limits compared with the standard limits for case 2.

Comparison of the calculated and standard limits shows that all values lie within the standard limits. It is usually a good idea
TABLE V

CAPACITOR LIMITS (IEEE STD. 18-1992) FOR CASE 1

\begin{tabular}{|c|c|c|c|}
\hline Item & Calculated (\%) & Limit (\%) & Exceeds limit \\
\hline rms voltage & 102.81 & 110. & No \\
\hline rms current & 105.96 & 135. & No \\
\hline kvar & 108.94 & 135. & No \\
\hline
\end{tabular}

to use capacitors with a higher voltage rating in some cases because of the voltage rise across the reactor at the fundamental frequency and due to the harmonic loading. Also, we can take into consideration $V_{C}, I_{C}$, and $Q_{C}$ as constraints in the optimization method to confirm that the results will lie within the standard limits.

The following is the illustration of the calculation of the reactor design specifications of the compensator for case 1 :

1) reactor impedance $=0.3090 \Omega$;

2) reactor rating $=0.819 \mathrm{mH}$;

3) harmonic current $=123.99 \mathrm{~A}$;

4) fundamental current $=353.90 \mathrm{~A}$.

Finally, the compensator cost $(C)$ is defined as

$$
\mathrm{C}=\mathrm{U}_{\mathrm{C}} * \mathrm{~S}_{\mathrm{C}}+\mathrm{U}_{\mathrm{L}} * \mathrm{~S}_{\mathrm{L}} \text {. }
$$

where $U_{C}$ and $U_{L}=$ are the unit cost of capacitor and inductor, and are considered to be constant parameters.

For capacitors and reactors, volt-ampere ratings are defined as [24]:

$$
\mathrm{S}_{\mathrm{C}}=\left[\frac{\sum_{\mathrm{K}} \mathrm{I}_{\mathrm{CK}} \mathrm{X}_{\mathrm{C}}}{\mathrm{K}}\right]\left[\sum_{\mathrm{K}} \mathrm{I}_{\mathrm{CK}}^{2}\right]^{1 / 2} \mathrm{kVA}
$$

and

$$
\mathrm{S}_{\mathrm{L}}=\left[\sum_{\mathrm{K}} \mathrm{I}_{\mathrm{CK}} \mathrm{KX}_{\mathrm{L}}\right]\left[\sum_{\mathrm{K}} \mathrm{I}_{\mathrm{CK}}^{2}\right]^{1 / 2} \mathrm{kVA} .
$$

Using (30)-(32) to calculate the cost of compensator for cases under study, the cost is U.S.\$ 6899.47 for case 1 and U.S.\$ 6587.04 for case 2 with $U_{C}$ and $U_{L}$ taken equal to U.S.\$2/kvar. Reference [2] describes the method for the evaluation of the parameters of the LC compensator for nonlinear loads taking into account cost constraints. Comparison of the results shows that the same power factor can be obtained by LC compensation at a lower cost, or a high power factor can be achieved by the LC compensator at the same cost.

Finally, the advantages of the presented method over the conventional approaches as mentioned above include the improvement in the accuracy of the solution and in the ability of the developed algorithm to guarantee convergence to the optimal solution. Using this method, the global optimal solution as well as the local optimums are determined. These additional information can be useful for performing a cost-benefit decision analysis before implementing the optimal LC compensator.

\section{CONCLUSION}

The recent trend of harmonic system standards, in fact, is deeply considering the random nature of voltage and current harmonics. The IEC publication 1000-3-6 uses probabilistic approaches both in comparing the actual current and voltage harmonic levels with the planning levels and in assessing the emission limits for distorting loads; the IEEE Std. 519 only slightly addresses the probabilistic application of harmonic distortion 
limits, but various efforts are in progress to more extensively include the probabilistic aspects.

An optimal LC compensator designed for the mean values of those random values does not necessarily render optimum average power factor, and may be overloaded when implemented to the time-varying case. Therefore, time variations of the harmonics and impedances must be considered in designing an optimal fixed LC compensator. If these characteristics of these time variations are priori not known, they can be found by measurements.

In this paper, a method is presented for minimizing the value of the voltage total harmonic distortion at the load bus where it is desired to maintain a given power factor with probabilistic source harmonics and impedances.

Two cases are tested, and the general performance of the proposed method is satisfactory, providing improvement of distortion levels and power factor correction, compared with other published results.

\section{APPENDIX}

DERIVATION OF (7)

From Fig. 1:

$$
\begin{aligned}
\mathrm{V}_{\mathrm{SK}} & =\mathrm{I}_{\mathrm{SK}} *\left(\mathrm{R}_{\mathrm{TK}}+\mathrm{j} \mathrm{X}_{\mathrm{TK}}\right)+\mathrm{V}_{\mathrm{LK}} \\
\mathrm{V}_{\mathrm{LK}} & =\left(\mathrm{I}_{\mathrm{SK}}-\mathrm{I}_{\mathrm{LK}}\right) * \mathrm{Z}_{\mathrm{CLK}} \cdot
\end{aligned}
$$

By simplification of the above equation and using (3)-(5) and (8)-(9), the supply current is obtained

$$
\mathrm{I}_{\mathrm{SK}}=\frac{\mathrm{V}_{\mathrm{SK}}(\mathrm{AR}+\mathrm{jBR})+\mathrm{I}_{\mathrm{LK}}(\mathrm{CR})}{\mathrm{A}_{\mathrm{IK}}+\mathrm{j} \mathrm{A}_{\mathrm{JK}}} .
$$

Then, the load voltage is given by

$$
\mathrm{V}_{\mathrm{LK}}=\frac{\mathrm{V}_{\mathrm{SK}}(\mathrm{CR})-\mathrm{I}_{\mathrm{LK}}(\mathrm{DR} * \mathrm{ER})}{\mathrm{A}_{\mathrm{IK}}+\mathrm{j} \mathrm{A}_{\mathrm{JK}}} .
$$

\section{REFERENCES}

[1] R. K. Hartana and G. G. Richards, "Comparing capacitive and LC compensators for power factor correction and voltage harmonic reduction," Elect. Power Syst. Res., vol. 17, no. 1, pp. 57-64, Jan. 1989.

[2] G. G. Richards, O. T. Tan, P. Klinkhachorn, and N. I. Santoso, "Costconstrained power factor optimization with source harmonics using LC compensators," IEEE Trans. Ind. Electron., vol. 34, no. 2, pp. 266-270, May 1987.

[3] G. G. Richards, P. Klinkhachorn, O. T. Tan, and R. K. Hartana, "Optimal LC compensators for nonlinear loads with uncertain nonsinusoidal source and load characteristics," IEEE Trans. Power Syst., vol. 4, no. 1, pp. 30-36, Feb. 1989.

[4] Y. Baghzouz, R. F. Burch, A. Capasso, A. Cavallini, A. E. Emanuel, M. Halpin, A. Imece, A. Ludbrook, G. Montanari, K. J. Olejniczak, P. Ribeiro, S. Rios-Marcuello, L. Tang, R. Thallam, and P. Verde, "Time-varying harmonics. I. Characterizing measured data," IEEE Trans. Power Del., vol. 13, no. 3, pp. 938-944, Jul. 1998.

[5] Y. Baghzouz, R. F. Burch, A. Capasso, A. Cavallini, A. E. Emanuel, M. Halpin, R. Langella, G. Montanari, K. J. Olejniczak, P. Ribeiro, S. Rios-Marcuello, F. Ruggiero, R. Thallam, A. Testa, and P. Verde, "Timevarying harmonics. II. Harmonic summation and propagation," IEEE Trans. Power Del., vol. 17, no. 1, pp. 279-285, Jan. 2002.

[6] A. Cavallini, G. Mazzanti, and G. C. Montanari, "Theoretical considerations on a probabilistic approach to economic optimization of multi-step power factor correction apparatus," in Proc. 8th Int. Conf. Harmonics Quality Power, vol. 2, Oct. 14-16, 1998, pp. 783-790.
[7] A. Cavallini, G. Mazzanti, G. C. Montanari, and C. Romagnoli, "Design of shunt capacitor circuits for power factor compensation in electrical systems supplying nonlinear loads: A probabilistic approach," IEEE Trans. Ind. Appl., vol. 34, no. 4, pp. 675-681, Jul./Aug. 1998.

[8] P. Klinkhachorn, R. K. Hartana, and B. Huner, "Microcomputer based estimator for power system parameters in the presence of harmonics," in Proc. IEEE Southeastcon, Apr. 11-13, 1988, pp. 529-532.

[9] I. El-Amin and I. Arafah, "Artificial neural networks for power systems harmonic estimation," in Proc. 8th Int. Conf. Harmonics Quality Power, vol. 2, Oct. 14-16, 1998, pp. 999-1009.

[10] T. Lobos, T. Kozina, and H. J. Koglin, "Power system harmonics estimation using linear least squares method and SVD," Proc. Inst. Elect. Eng., Gen., Transm. Distrib., vol. 148, no. 6, pp. 567-572, Nov. 2001.

[11] L. Siqueira, A. M. Carneiro, and M. De Oliveira, "Assessment of harmonic distortions on power and energy measurements," in Proc. 9th Int. Conf. Harmonics Quality Power, vol. 1, Oct. 1-4, 2000, pp. 105-109.

[12] R. Yacamini, "Power system harmonics. II. Measurements and calculations," Power Eng. J., vol. 9, no. 1, pp. 51-56, Feb. 1995.

[13] M. F. McGranaghan, R. C. Dugan, J. A. King, and W. T. Jewell, "Distribution feeder harmonic study methodology," IEEE Trans. Power App. Syst., vol. PAS-103, no. 12, pp. 3663-3671, Dec. 1984

[14] M. Schilling, A. M. L. da Silva, R. Billington, and M. A. El-Kady, "Bibliography on power system probabilistic analysis," IEEE Trans. Power Syst., vol. 5, no. 1, pp. 1-11, Feb. 1990.

[15] CIGRE, Working Group 03 of Study Committee 38 (Power System Analysis and Techniques): "Power System Reliability Analysis. Application Guide”. London, U.K.: Kelley-Regnier, 1987.

[16] I. S. Gradshteyn and L. M. Ryzhik, Tables of Integrals, Series and Products. Cambridge, U.K.: Cambridge Univ. Press, 1980.

[17] IEEE Recommended Practices and Requirements for Harmonic Control in Electrical Power Systems, IEEE Std. 519-1992, 1992.

[18] IEEE Standards for Shunt Power Capacitors, IEEE Std. 18-2002, 2002.

[19] S. S. Rao, Engineering Optimization: Theory and Practice, 3 ed: WileyInterscience, 1996.

[20] M. Ben-Daya and K. S. Al-Sultan, "A new penalty function algorithm for convex quadratic programming," Eur. J. Oper. Res., vol. 101, pp. 155-163, 1997.

[21] A. F. Zobaa, "A new approach for voltage harmonic distortion minimization,” Elect. Power Syst. Res. J., vol. 70, no. 3, pp. 253-260, Aug. 2004.

[22] I. M. El-Amin, S. O. Duffuaa, and A. U. Bawah, "Optimal shunt compensators at nonsinusoidal bus bars," IEEE Trans. Power Syst., vol. 10, no. 2, pp. 716-723, May 1995.

[23] IEEE Guide for the Application, Specification, and Testing of PhaseShifting Transformers, IEEE Std. C57.135-2001, 2002.

[24] IEEE Guide for the Application and Specification of Harmonic Filters, IEEE Std. 1531-2003, 2003.

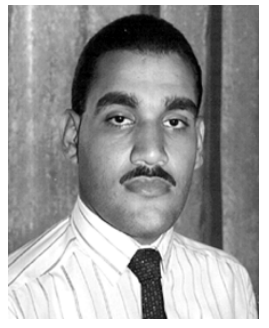

Ahmed Faheem Zobaa (M'01-SM'04) received the B.Sc. (Hons.), M.Sc., and Ph.D. degrees in electrical power and machines from the Faculty of Engineering at Cairo University, Giza, Egypt, in 1992, 1997, and 2002, repsectively.

Currently, he is an Assistant Professor in the Department of Electrical Power and Machines, Faculty of Engineering, Cairo University. He was an Instructor in the Department of Electrical Power and Machines, with the Faculty of Engineering at Cairo University from 1992 to 1997 and Teaching Assistant from 1997 to 2002. His areas of research include harmonics, compensation of reactive power, power quality, photovoltaics, wind energy, education, and distance learning. He is an Editorial Board member for Electric Power Components \& Systems Journal, International Journal of Emerging Electric Power Systems, International Journal of Computational Intelligence, and WSEAS Transactions on Power Systems. He is an Editor for IEEE POWER ENGINEERING LETTERS and IEEE TRANSACTIONS ON ENERGY CONVERSION. Also, he is an Associate Editor for IEEE TRANSACTIONS ON INDUSTRIAL ELECTRONICS, Electrical Power Quality and Utilization Journal, International Journal of Power and Energy Systems, International Journal on Modeling and Simulation, International Journal of Energy Technology and Policy, and Neurocomputing Journal.

Dr. Zobaa is a member of the IEEE Power Engineering/Industry Applications/Industrial Electronics/Power Electronics Societies, Institution of Electrical Engineers, the International Association of Science and Technology for Development, and the International Solar Energy Society. 